\title{
EVALUASI ASPEK FISIK DAN KENYAMANAN JALUR PEDESTRIAN MELALUI ANALISIS PERSEPSI MASYARAKAT DI JALAN DIPONEGORO SALATIGA
}

\section{Evaluation of Physical and Amenity Aspect of Pedestrian Track Using the Public Perception Analysis on Jalan Diponegoro Salatiga}

\author{
Henny Mustikawati \\ Jurusan Agroteknologi, Fakultas \\ Pertanian dan Bisnis, Universitas Kristen \\ Satya Wacana \\ Email: 512012037@student.uksw.edu

\section{Nugraheni Widyawati} \\ Jurusan Agroteknologi, Fakultas \\ Pertanian dan Bisnis, Universitas Kristen \\ Satya Wacana
}

\begin{abstract}
Pedestrian track on Jalan Diponegoro Salatiga when 2017th has suffered by some damage and has not been functioned properly. Pedestrian track is used for trading activities and for parking area. Therefore is needed to inspect with research analysis. The research was carried on February till March 2017 on Jalan Diponegoro Salatiga. The research is evaluation of physical and comfort aspect of pedestrian of Jalan Diponegoro Salatiga based on the public perception. The purpose are knowing public perception about the physical and amenitu aspect, knowing maintener priority and knowing the appropriate pedestrian track based on the result of perception and priority handling with redesain. The type of research is descriptive qualitative. Stages from research are observation, questionnaires with 100 respondents, analysis and redesign. Analysis of questionnaire using performance and importance analysis. Making redesign using sketchup software based on the results of perception and the regulations. The results of the public perception is physical of pedestrian track on Jalan Diponegoro Salatiga was low and amenity the pedestrian was good enough. The results performance and importance analysis is vegetation nursing, lamp function of pedestrian track, condition of paving, and cleaness of pedestrian track are being main priority for repair and the maintainer give more attention.
\end{abstract}

Keywords: amenity, evaluation, pedestrian, physical aspects, public perception

\section{PENDAHULUAN}

Jalan Diponegoro Salatiga merupakan jalan arteri primer yang menghubungkan Kabupaten Semarang dan Kabupaten Boyolali. Jalan Diponegoro Salatiga mencakup sepanjang Terminal Lama Soka hingga Tugu Taman Sari, dengan panjang hingga 2.7 kilometer, lebar jalan 9-10 meter, dan lebar jalur pejalan kaki 2-3 meter.

Jalan Diponegoro Salatiga merupakan jalan yang digunakan untuk menuju pusat Kota Salatiga, sarana yang digunakan untuk menuju pusat kota menggunakan transportasi umum, transportasi pribadi dan dengan berjalan kaki. Fasilitas yang digunakan untuk pedestrian (pejalan kaki) melakukan aktivitasnya adalah jalur trotoar yang sering disebut dengan jalur pedestrian.

Berdasarkan Pedoman Perencanaan, Penyediaan, dan Pemanfaatan Prasarana dan Sarana Jaringan Pejalan Kaki, jalur pedestrian di sepanjang Jalan Diponegoro Salatiga dapat dikatakan belum menjadi jalur pedestrian yang ideal karena belum memenuhi kriteria baku. Banyak pedestrian yang berjalan tidak di jalur pejalan kaki, karena jalur pedestrian yang berubah fungsi menjadi tempat berjualan oleh para pedagang kaki lima (PKL), tempat parkir kendaraan bermotor, dan fisik jalur pedestrian sudah mengalami banyak kerusakan.

Untuk mendapatkan data kondisi jalur pedestrian yang sesungguhnya, dapat ditempuh melalui penjaringan persepsi masyarakat di sekitarnya. Selama ini belum dilakukan penelitian mengenai hal ini, sehingga penelitian ini bertujuan untuk mengevaluasi aspek fisik dan kenyamanan jalur pedestrian dengan melibatkan persepsi dari para pedestrian di Jalan Diponegoro Salatiga.

\section{METODE PENELITIAN}

Metode yang digunakan dalam penelitian adalah dengan menggunakan kuesioner. Berikut langkah-langkah dalam penelitian:

\section{a) Observasi dan inventarisasi}

Observasi bertujuan untuk dapat mengetahui kondisi fisik yang ada di jalur pedestrian, mengetahui keramaian jalur pedestrian dan mengetahui fasilitas apa saja yang ada di jalur pedestrian.

b) Pembagian zona kawasan

Lokasi penelitian di jalur pejalan kaki sepanjang 2.7 kilometer, ditetapkan oleh peneliti dibagi menjadi 5 (lima) zona pengamatan. Setiap zona nantinya terdapat titik-titik tertentu yang dianggap strategis dalam melakukan pengamatan, misalnya jalur pejalan kaki yang ramai, jalur pedestrian yang terdapat banyak PKL, dan sebagainya. Zona penelitian yakni pada:

1) Zona 1 (Depan SD Negeri II Salatiga)

2) Zona 2 (Depan Universitas Kristen Satya Wacana)

3) Zona 3 (Depan SMP Pangudi Luhur Salatiga)

4) Zona 4 (Depan SD Sidorejo Lor I)

5) Zona 5 (Depan Diponegoro Futsal)

c) Pengumpulan data

Pengumpulan data menggunakan metode wawancara menggunakan kuisioner. Sebelum melakukan wawancara, peneliti menetapkan jumlah responden atau sampel. Metode pengambilan sampel dengan cara purposive sample yang tujuannya pada kedalaman pada penghayatan objek penelitian. Responden diambil dari pengguna yang beraktivitas di jalur pedestrian pada saat-saat terpilih yang telah ditentukan disetiap zona. Para responden adalah 
mahasiswa atau pelajar, masyarakat umum (pedagang, karyawan, penduduk sekitar), pengelola jalur pejalan kaki dan petugas yang merawat jalur pedestrian di Jalan Diponegoro Salatiga.

Dalam penelitian ini jumlah volume populasi pejalan kaki diambil dari sampel sebagai parameter perkiraan, yaitu sebesar $10 \%$ dari jumlah populasi yang diperoleh dari hasil perhitungan peneliti, artinya besar sampel adalah $10 \%$ dari populasi. Maka besar sampel dalam penelitian ini ditetapkan sampel berjumlah 100 orang pejalan kaki.

d) Analisis data

Analisis data dilakukan setelah semua data terkumpul dengan menggunakan importance performance analysis. Model ini bertujuan untuk mengukur hubungan persepsi pengguna jalur pedestrian dan prioritas peningkatan fasilitas yang dikenal sebagai "quadran analysis". Model Importance Performance Analysis (IPA) dibagi menjadi empat kuadran.

e) Desain ulang

Desain ulang menggunakan Google SketchUp 2015, desain ulang jalur pedestrian akan berbentuk 3 dimensi (3D), sehingga desain ulang akan hampir seperti nyata. Desain ulang disesuaikan dengan hasil analisis data kuisioner, wawancara dengan responden 100 orang dan disesuaikan juga dengan aturan dan kebijakan yang berlaku.

\section{HASIL DAN PEMBAHASAN}

\section{Letak dan Lokasi Penelitian}

Jalan Diponegoro Salatiga merupakan jalan arteri primer yang menghubungkan Kabupaten Semarang dan Kabupaten Boyolali. Jalan Diponegoro Salatiga mencakup sepanjang Terminal Lama Soka hingga Tugu Taman Sari, dengan panjang 2.7 kilometer, lebar jalan 9-10 meter, dan lebar jalur pedestrian 2-3 meter. Sepanjang Jalan Diponegoro Salatiga sebagian besar merupakan kawasan pendidikan, yang terdapat beberapa sekolah dan universitas, kantor pemerintahan, sarana kesehatan, perdagangan dan jasa, peribadatan dan pemukiman.

\section{Penilaian Masyarakat Terhadap Jalur Pedestrian di Jalan Diponegoro Salatiga}

\section{Penilaian Masyrakat Terhadap Aspek Fisik Jalur Pedestrian di Jalan Diponegoro Salatiga}

Nilai performance adalah nilai yang menujukkan kondisi dari atribut yang dinilai. Aspek fisik terdiri dari 3 aspek yang dinilai, yakni vegetasi, lampu penerangan dan perkerasan. Setiap aspek memiliki atribut yang dinilai kondisi atau nilai performancenya. Pada Tabel 1 dapat diketahui bahwa nilai rata-rata tertinggi adalah 2.74 pada atribut fungsi vegetasi sebagai peneduh. Nilai ini berarti atribut berada pada kondisi yang cukup baik. Hal tersebut dikarenakan responden beranggapan bahwa vegetasi yang berada pada jalur pedestrian Jalan Diponegoro Salatiga sudah cukup berfungsi sebagai peneduh. Nilai rata-rata terendah adalah 1.71 pada atribut kondisi paving, nilai tersebut menujukkan bahwa kondisi paving di jalur pedestrian Jalan Diponegoro Salatiga kurang baik, hal tersebut dikarenakan keadaan atau kondisi perkerasan di Jalan Diponegoro Salatiga sudah banyak yang rusak, sehingga responden menilai bahwa perkerasan di jalur pedestrian Jalan Diponegoro Salatiga memiliki kondisi yang kurang baik.
Pada Tabel 1 dapat diketahui nilai rata-rata keseluruhan yang menunjukkan kondisi fisik dari jalur pedestrian di Jalan Diponegoro Salatiga, nilai rata-rata keseluruhan adalah 2.30 yang menunjukkan bahwa kondisi fisik di Jalan Diponegoro Salatiga masih buruk, dari segi vegetasi, lampu penerangan dan perkerasan. Dari hasil persepsi masyarakat yang menyatakan bahwa kondisi fisik jalur pedestrian yang masih buruk, maka dilakukan desain agar jalur pedestrian dapat digunakan lebih optimal oleh pejalan kaki.

Selain mengetahui kondisi dari jalur pedestrian atau performance, pembagian kuisioner juga mengetahui nilai importance atau tingkat kepentingan dari setiap atribut, berikut penilaian importance aspek fisik di Jalan Diponegoro Salatiga.

Nilai importance adalah nilai yang menyatakan tingkat kepentingan responden terhadap atribut yang diukur, nilai importance dapat dikatakan sebagai harapan responden terhadap atribut untuk dikelola lebih baik lagi, dengan menilai kepentingan suatu atribut. Pada Tabel 2 dapat diketahui nilai rata-rata importance tertinggi adalah 4.95, yakni pada atribut posisi letak lampu. Nilai ini menyatakan bahwa atribut sangat penting bagi responden, hal tersebut dikarenakan menurut responden posisi letak lampu penerangan mempengaruhi pencahayaan pada jalur pedestrian, sehingga jika posisi letak lampu tidak sesuai, maka fungsi penerangan tidak maksimal, sehingga responden menilai posisi letak lampu sangat penting dalam sebuah jalur pedestrian.

Nilai rata-rata importance terendah adalah 4.73 yakni pada atribut keindahan paving. Nilai 4.73 menyatakan bahwa atribut juga sangat penting atau sangat butuh bagi responden, namun nilai 4.73 merupakan nilai yang paling rendah dibandingkan dengan nilai rata-rata importance lainnya, hal tersebut dikarenakan keindahan paving menurut responden kurang penting bagi responden atau masyarakat dibandingkan dengan atribut yang lainnya. Dari hasil rata-rata keseluruhan nilai importance pada aspek fisik yang bernilai 4.85 yang berarti bahwa semua atribut aspek fisik sangat penting atau sangat butuh bagi responden, maka keajiban dari pengelola adalah mengelola setiap atribut dengan baik, agar setiap kebutuhan dalam aspek fisik responden terpenuhi.

\section{Penilaian Masyarakat Terhadap Aspek Kenyamanan Jalur Pedestrian di Jalan Diponegoro Salatiga}

Pada Tabel 3 dapat diketahui nilai performance dari aspek kenyamanan, nilai performance sendiri merupakan nilai yang menyatakan kondisi dari setiap atribut yang di nilai atau diukur. Pada Tabel 3 dapat diketahui nilai rata-rata performance tertinggi adalah 2.83 pada atribut lebar jalur pedestrian, nilai 2.83 menunjukkan bahwa atribut lebar jalur pedestrian sudah cukup baik bagi responden, untuk lebar jalur pedestrian di Jalan Diponegoro Salatiga berkisar 2-3 meter, dan hal tersebut sudah cukup baik atau sudah cukup nyaman saat digunakan. Responden atau masyarakat pengguna jalur pedestrian saat berpapasan tidak saling menabrak, hal tersebut merupakan alasan mengapa lebar jalur pedestrian di Jalan Diponegoro Salatiga sudah baik. Nilai rata-rata performance terendah adalah 2.29 pada atribut kebersihan jalur pedestrian. Nilai ini menunjukkan bahwa atribut berada pada kondisi buruk, hal tersebut dikarenakan jalur pedestrian di Jalan Diponegoro Salatiga menurut responden memang masih banyak ditemukan sampah dan terlihat kotor, sehingga 
Tabel 1. Penilaian Performance Aspek Fisik di Jalan Diponegoro Salatiga

\begin{tabular}{|c|c|c|c|c|c|c|c|c|}
\hline \multicolumn{9}{|c|}{ Performance } \\
\hline Aspek fisik & $\begin{array}{l}\text { Atribut yang } \\
\text { diukur }\end{array}$ & $\begin{array}{c}\text { SD } \\
\text { Negeri } \\
\text { II }\end{array}$ & UKSW & $\begin{array}{c}\text { SMP } \\
\text { Pangudi } \\
\text { Luhur }\end{array}$ & $\begin{array}{c}\text { SD } \\
\text { Sidorejo } \\
\text { Lor I }\end{array}$ & $\begin{array}{c}\text { Diponegoro } \\
\text { Futsal }\end{array}$ & Pengelola & $\begin{array}{l}\text { Rata- } \\
\text { rata }\end{array}$ \\
\hline \multirow[t]{4}{*}{ Vegetasi } & $\begin{array}{l}\text { Keindahan } \\
\text { vegetasi }\end{array}$ & 2.50 & 2.33 & 2.28 & 2.28 & 2.28 & 2.10 & 2.30 \\
\hline & $\begin{array}{l}\text { Jumlah } \\
\text { vegetasi }\end{array}$ & 2.33 & 2.78 & 2.72 & 2.72 & 2.44 & 3.30 & 2.72 \\
\hline & $\begin{array}{l}\text { Fungsi } \\
\text { vegetasi } \\
\text { sebagai } \\
\text { peneduh }\end{array}$ & 2.17 & 2.78 & 3.00 & 2.72 & 2.56 & 3.20 & 2.74 \\
\hline & $\begin{array}{l}\text { Perawatan } \\
\text { vegetasi }\end{array}$ & 2.00 & 2.17 & 1.94 & 1.78 & 1.78 & 3.00 & 2.11 \\
\hline \multirow[t]{3}{*}{$\begin{array}{l}\text { Lampu } \\
\text { Penerangan }\end{array}$} & $\begin{array}{l}\text { Posisi letak } \\
\text { lampu }\end{array}$ & 2.56 & 2.61 & 2.33 & 2.44 & 2.33 & 2.20 & 2.41 \\
\hline & $\begin{array}{l}\text { Jumlah } \\
\text { lampu }\end{array}$ & 2.61 & 2.67 & 2.28 & 2.33 & 2.28 & 2.60 & 2.46 \\
\hline & Fungsi lampu & 2.22 & 2.56 & 1.94 & 2.44 & 1.94 & 1.80 & 2.15 \\
\hline \multirow[t]{3}{*}{ Perkerasan } & $\begin{array}{l}\text { Keindahan } \\
\text { paving }\end{array}$ & 2.22 & 2.50 & 2.17 & 2.00 & 1.78 & 1.90 & 2.10 \\
\hline & $\begin{array}{l}\text { Material } \\
\text { paving }\end{array}$ & 2.33 & 2.17 & 2.17 & 2.17 & 1.94 & 3.00 & 2.30 \\
\hline & $\begin{array}{l}\text { Kondisi } \\
\text { paving }\end{array}$ & 2.06 & 1.83 & 1.33 & 1.61 & 1.72 & 1.70 & 1.71 \\
\hline
\end{tabular}

Keterangan: Performance 0.5 - 1.4; sangat buruk; 1.5 - 2.4: buruk; 2.5 - 3.4: cukup baik; 3.5 - 4.4: baik; 4.5 - 5.4 : sangat baik

banyak responden menilai bahwa kebersihan di jalur pedestrian masih buruk.

Nilai rata-rata performance pada aspek kenyamanan menunjukkan kenyamanan pada jalur pedestrian di Jalan Diponegoro Salatiga. Pada Tabel 3 dapat diketahui bahwa nilai rata-rata keseluruhan performance adalah 2.52, dan nilai tersebut menunjukkan bahwa kenyamanan di jalur pedestrian Jalan Diponegoro Salatiga cukup baik atau cukup nyaman.

Selain mengetahui kondisi dari jalur pedestrian atau performance, pembagian kuisioner juga mengetahui nilai importance atau tingkat kepentingan dari setiap atribut. Nilai importance merupakan nilai yang menyatakan tingkat kepentingan responden terhadap atribut yang diukur, pada aspek kenyamanan terdapat tiga atribut yang dinilai, yakni sirkulasi jalur pedestrian, kebersihan dan lebar jalur pedestrian. Pada Tabel 4 dapat diketahui nilai rata-rata importance tertinggi adalah 4.94 pada atribut kebersihan jalur pedestrian, nilai ini menunjukkan bahwa kebersihan jalur pedestrian sangat penting bagi responden dan mempengarihi kenyamanan dari responden, sehingga responden menilai bahwa kebersihan jalur pedestrian sangat penting atau sangat butuh bagi responden. Nilai performance terendah adalah 4.90 pada atribut sirkulasi jalur pedestrian, nilai tersebut juga menyatakan bahwa atribut juga sangat penting bagi responden, namun nilai 4.92 lebih rendah dibandingkan dengan nilai kebersihan dan lebar jalur pedestrian, hal tersebut dikarenakan responden menilai bahwa sirkulasi jalur pedestrian tidak terlalu penting dibandingkan dengan kebersihan dan lebar jalur pedestrian.

Pada Tabel 4 dapat mengetahui rata-rata keseluruhan importance pada aspek kenyamanan, nilai rata-rata importance pada aspek kenyamanan adalah 4.92, yang menunjukkan bahwa atribut pada aspek kenyamanan sangat penting dan mempengaruhi kenyamanan dari responden.

Prioritas penanganan pada aspek fisik dan kenyamanan di jalur pedestrian Jalan Diponegoro Salatiga.

Dari penilaian performance dan importance aspek fisik dan kenyamanan jalur pedestrian di Jalan Diponegoro Salatiga, dapat dibuat diagram kartesius untuk mengetahui prioritas penanganan dari setiap atribut aspek fisik dan kenyamanan.

Diagram kartesius merupakan diagram yang menunjukkan prioritas penanganan, pada diagram kartesius terdapat empat kuadran, yakni kuadran I (prioritas utama), kuadran II (prioritas prestasi), kuadran III (prioritas rendah), dan kuadran IV (berlebihan). Pada diagram I dapat diketahui prioritas penanganan pada atribut aspek fisik dan aspek kenyamanan. Pada diagram I dapat dilihat bahwa:

1) Atribut yang berada pada kuadran I atau prioritas utama adalah perawatan vegetasi, fungsi lampu penerangan, kondisi paving dan kebersihan jalur pedestrian.

2) Atribut yang berada pada kuadran II atau prioritas prestasi adalah letak lampu, jumlah lampu, sirkulasi, dan lebar jalur pedestrian.

3) Atribut yang berada pada kuadran III atau prioritas rendah adalah keindahan vegetasi, keindahan paving, dan material paving.

4) Atribut yang berada pada kuadran IV atau berlebihan adalah jumlah vegetasi dan fungsi vegetasi sebagai peneduh. 
Tabel 2. Penilaian Importance Aspek Fisik di Jalan Diponegoro Salatiga

\begin{tabular}{|c|c|c|c|c|c|c|c|c|}
\hline \multicolumn{9}{|c|}{ Importance } \\
\hline Aspek fisik & $\begin{array}{l}\text { Atribut yang } \\
\text { diukur }\end{array}$ & $\begin{array}{c}\text { SD } \\
\text { Negeri } \\
\text { II }\end{array}$ & UKSW & $\begin{array}{c}\text { SMP } \\
\text { Pangudi } \\
\text { Luhur }\end{array}$ & $\begin{array}{c}\text { SD } \\
\text { Sidorejo } \\
\text { Lor I }\end{array}$ & $\begin{array}{c}\text { Diponegoro } \\
\text { Futsal }\end{array}$ & Pengelola & $\begin{array}{r}\text { Rata- } \\
\text { rata }\end{array}$ \\
\hline \multirow[t]{4}{*}{ Vegetasi } & $\begin{array}{l}\text { Keindahan } \\
\text { vegetasi }\end{array}$ & 4.83 & 4.89 & 4.61 & 4.83 & 5.00 & 4.8 & 4.83 \\
\hline & $\begin{array}{l}\text { Jumlah } \\
\text { vegetasi }\end{array}$ & 4.83 & 4.78 & 4.61 & 4.72 & 5.00 & 4.70 & 4.77 \\
\hline & $\begin{array}{l}\text { Fungsi } \\
\text { vegetasi } \\
\text { sebagai } \\
\text { peneduh }\end{array}$ & 4.89 & 4.94 & 4.50 & 4.72 & 4.94 & 4.80 & 4.80 \\
\hline & $\begin{array}{l}\text { Perawatan } \\
\text { vegetasi }\end{array}$ & 4.89 & 4.83 & 4.61 & 4.89 & 5.00 & 5.00 & 4.87 \\
\hline \multirow[t]{3}{*}{$\begin{array}{l}\text { Lampu } \\
\text { penerangan }\end{array}$} & $\begin{array}{ll}\text { Posisi } & \text { letak } \\
\text { lampu }\end{array}$ & 4.89 & 4.94 & 4.89 & 5.00 & 5.00 & 5.00 & 4.95 \\
\hline & $\begin{array}{l}\text { Jumlah } \\
\text { lampu }\end{array}$ & 4.89 & 4.89 & 4.67 & 5.00 & 4.94 & 4.9 & 4.88 \\
\hline & Fungsi lampu & 4.89 & 4.94 & 4.72 & 5.00 & 5.00 & 5.00 & 4.93 \\
\hline \multirow[t]{3}{*}{ Perkerasan } & $\begin{array}{l}\text { Keindahan } \\
\text { paving }\end{array}$ & 4.72 & 4.78 & 4.67 & 4.67 & 4.94 & 4.60 & 4.73 \\
\hline & $\begin{array}{l}\text { Material } \\
\text { paving }\end{array}$ & 4.83 & 4.94 & 4.78 & 4.67 & 4.89 & 5.00 & 4.85 \\
\hline & $\begin{array}{l}\text { Kondisi } \\
\text { paving }\end{array}$ & 4.83 & 4.94 & 4.78 & 4.94 & 5.00 & 5.00 & 4.92 \\
\hline \multicolumn{8}{|c|}{ Rata-rata keseluruhan } & 4.85 \\
\hline
\end{tabular}

Keterangan: Importance 0.5 - 1.4: sangat butuh; 1.5 - 2.4: butuh; 2.5 - 3.4: cukup butuh; 3.5 - 4.4 : butuh; 4.5 - 5.4 : sangat butuh

Tabel 3. Penilaian Performance Aspek Kenyamanan di Jalan Diponegoro Salatiga

\begin{tabular}{|c|c|c|c|c|c|c|c|c|}
\hline \multicolumn{9}{|c|}{ Performance } \\
\hline Aspek & $\begin{array}{l}\text { Atribut yang } \\
\text { diukur }\end{array}$ & $\begin{array}{c}\text { SD } \\
\text { Negeri } \\
\text { II }\end{array}$ & UKSW & $\begin{array}{c}\text { SMP } \\
\text { Pangudi } \\
\text { Luhur }\end{array}$ & $\begin{array}{c}\text { SD } \\
\text { Sidorejo } \\
\text { Lor I }\end{array}$ & $\begin{array}{c}\text { Diponegoro } \\
\text { Futsal }\end{array}$ & Pengelola & $\begin{array}{l}\text { Rata- } \\
\text { rata }\end{array}$ \\
\hline \multirow[t]{3}{*}{ Kenyamanan } & $\begin{array}{l}\text { Sirkulasi jalur } \\
\text { pedestrian }\end{array}$ & 2.28 & 2.56 & 2.28 & 3.11 & 2.22 & 2.20 & 2.44 \\
\hline & $\begin{array}{l}\text { Kebersihan } \\
\text { jalur } \\
\text { pedestrian }\end{array}$ & 2.00 & 2.28 & 2.17 & 2.61 & 2.89 & 2.80 & 2.29 \\
\hline & $\begin{array}{l}\text { Lebar jalur } \\
\text { pedestrian }\end{array}$ & 2.94 & 2.56 & 2.71 & 3.17 & 2.61 & 3.00 & 2.83 \\
\hline
\end{tabular}

Rata-rata keseluruhan

Keterangan: Importance 0.5 - 1.4: sangat butuh; 1.5 - 2.4: butuh; 2.5 - 3.4: cukup butuh; 3.5 - 4.4 : butuh; 4.5 - 5.4 : sangat butuh

Kuadran I atau prioritas utama adalah daerah yang menyatakan bahwa atribut memiliki nilai kondisi lapangan atau performance lebih rendah dari rata-rata, dan nilai harapan atau importance diatas atau melebihi ratarata. Pada Gambar 1, dapat dilihat bahwa atribut yang masuk pada prioritas pertama adalah perawatan vegetasi, fungsi lampu, kondisi paving dan kebersihan paving. Pihak pengelola berkewajiban memberikan perhatian yang lebih dan memberikan sumberdaya yang lebih pada atribut yang berada pada kuadran I atau prioritas pertama. Atribut yang masuk pada prioritas pertama ini, merupakan atribut yang dinilai kondisinya dalam keadaan buruk dan sangat penting dan mempengaruhi kegiatan di jalur pedestrian, sehingga setiap atribut yang berada pada kuadran I ini perlu lebih diperhatikan.

Kuadran II merupakan kuadran atau wilayah yang menunjukkan atribut memiliki nilai performance dan importance melebihi rata-rata. Atribut yang berada pada kuadran II merupakan atribut yang sudah sesuai dengan harapan responden, sehingga pihak pengelola hanya perlu merawat dan mempertahankan kondisi atribut. Atribut yang berada pada kuadran II atau prioritas prestasi adalah letak lampu, jumlah lampu, sirkulasi, dan lebar jalur pedestrian. 


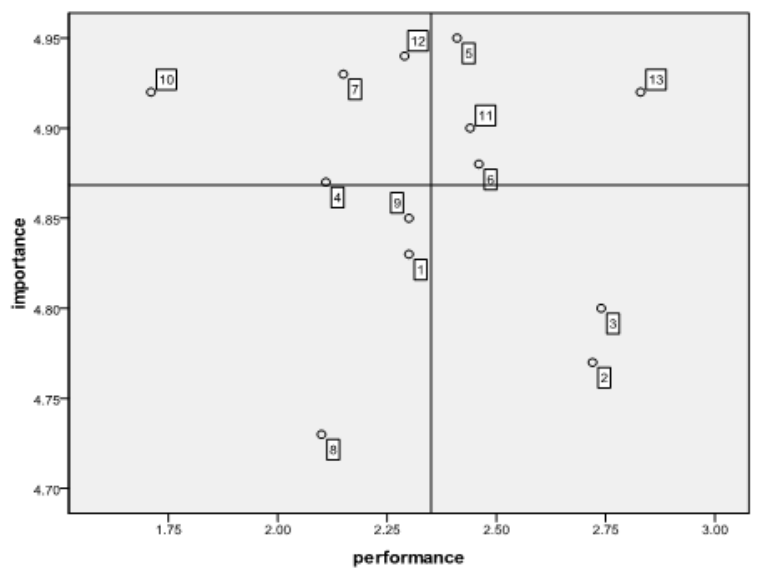

Gambar 1. Prioritas Penanganan Jalur Pedestrian di Jalan Diponegoro Salatiga

Kuadran III adalah daerah atau kuadran yang menunjukkan atribut memiliki nilai performance dan importance di bawah rata-rata atau rendah. Atribut yang berada pada kuadran III ini mempunyai tingkat prioritas yang rendah daripada atribut yang lainnya, sehingga pihak manajemen atau pengelola tidak perlu lagi memprioritaskan atribut ini, namun pihak pengelola tetap berkewajiban untuk tetap menjaga atribut yang ada. Atribut yang berada pada kuadran III atau prioritas rendah adalah keindahan vegetasi, keindahan paving, dan material paving.

Kuadaran IV adalah daerah yang menunjukkan atribut memiliki nilai performance yang tinggi atau diatas rata-rata, tetapi importance atau harapan dibawah rata-rata atau rendah. Atribut yang berada pada kuadran ini dianggap tidak terlalu penting, namun kondisinya sudah memuaskan. Pihak pengelola perlu mengalokasikan atribut yang terkait pada kuadran ini kepada atribut lain yang membutuhkan prioritas penanganan lebih tinggi. Atribut yang berada pada kuadran IV atau berlebihan adalah jumlah vegetasi dan fungsi vegetasi sebagai peneduh.

\section{Desain Ulang Jalur Pedestrian}

Desain ulang jalur pedestrian di Jalan Diponegoro Salatiga disesuaikan dengan hasil persepsi dan analisis data importance performance. Hasil persepsi masyarakat menunjukkan bahwa fisik jalur pedestrian Salatiga buruk, sehingga dilakukan desain ulang atau penataan ulang jalur pedestrian, yang berguna sebagai rekomendasi bagi pengelola. Hasil analisis data, hal yang menjadi prioritas utama dalam penanganan adalah perawatan vegetasi, fungsi lampu penerangan, kondisi paving dan kebersihan jalur pedestrian. Dari prioritas penangan tersebut, maka desain ulang jalur pedestrian akan lebih memprioritaskan pada vegetasi, lampu penerangan dan perkerasan atau paving (Gambar 2 hingga Gambar 6).

Perbedaan jalur pedestrian antara sebelum dan sesudah di desain ulang antara lain:

a) Lampu jalur pedestrian

Pada prioritas penanganan, salah satu prioritas utama adalah fungsi lampu penerangan, sehingga dalam desain ulang menggunakan lampu pedestrian dengan ketinggian 4 meter, dan letak lampu penerangan setiap 10 meter sehingga fungsi lampu penerangan dapat lebih optimal.
Lampu penerangan memiliki tempat menggantung tanaman hias ataupun banner sebagai daya tarik tersendiri.

b) Vegetasi

Pada prioritas penanganan, salah satu prioritas utama adalah perawatan vegetasi, sehingga dalam pemilihan vegetasi pada desain ulang jalur pedestrian menggunakan vegetasi yang mudah dirawat dan tidak perlu perawatan yang khusus. Pemilihan vegetasi yang tepat akan mempermudah pengelola dalam perawatan, sehingga vegetasi yang terdapat di jalur pedestrian lebih terlihat baik dan terawat

c) Tempat sampah

Pada prioritas penanganan, salah satu prioritas utama adalah kebersihan. Jalur pedestrian di Jalan Diponegoro Salatiga masih banyak ditemukan sampah yang dibuang sembarangan, dan jumlah tempat sampah yang kurang mencukupi, sehingga pada desain ulang ditambah dengan tempat sampah yang diletakkan setiap 20 meter. Peletakan tempat sampah ini diharapkan dapat mengurangi pedestrian yang membuang sampah sembarangan. Desain tempat sampah dipilih dengan bahan yang tidak mudah rusak

\section{d) Kursi}

Salah satu fungsi jalur pedestrian adalah tempat berinteraksi masyarakat, sehingga perlu adanya bangku atau kursi yang dapat digunakan untuk tempat berinteraksi dan beristirahat. Peletakan kursi setiap 10 meter sesuai dengan aturan dan ketentuan yang ada.

\section{e) Perkerasan}

Pada prioritas penanganan, salah satu prioritas utama adalah kondisi paving, dikarenakan kondisi paving tahun 2017 banyak mengalami kerusakan. Pada desain ulang jalur pedestrian di Jalan Diponegoro Salatiga, paving menggunakan batuan alam adesit. Pemilihan batuan alam adesit dengan tujuan lebih kokoh dan tidak licin, sehingga paving di jalur pedestrian tidak mudah rusak.

f) Lain-lain

1) Tinggi jalur pedestrian sesuai dengan peraturan yakni 0.25 meter

2) Desain ulang jalur pedestrian lebih menonjolkan budaya jawa dengan adanya signage atau papan yang berisi Paribasan Jawa sebagai daya tarik pengguna jalur pedestrian.

\section{SIMPULAN}

Berdasarkan hasil analisis persepsi masyarakat terhadap jalur pedestrian di Jalan Diponegoro Salatiga, dapat disimpulkan bahwa:

a) Hasil perhitungan analisis yang telah diperoleh dari jumlah responden sebanyak 100 orang pejalan kaki, memberikan keterangan bahwa fisik jalur pedestrian di Jalan Diponegoro Salatiga buruk dan persepsi masyarakat terhadap kenyamanan jalur pedestrian di Jalan Diponegoro Salatiga adalah cukup baik atau cukup nyaman.

b) Prioritas penanganan di jalur pedestrian Jalan Diponegoro Salatiga adalah perawatan vegetasi, fungsi lampu penerangan, kondisi paving dan kebersihan jalur pedestrian. 


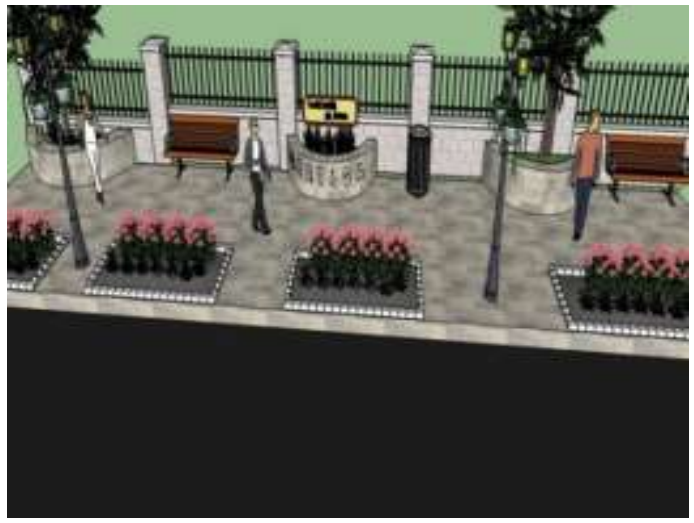

Gambar 2. Desain Ulang Jalur Pedestrian Depan SD Negeri II Salatiga

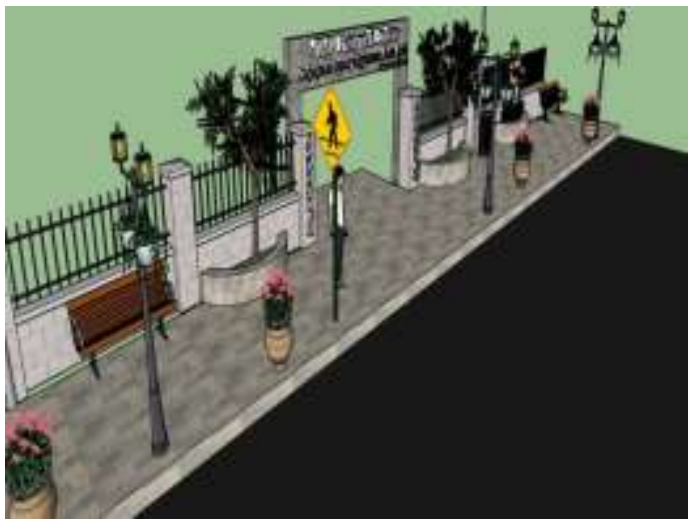

Gambar 4. Desain Ulang Jalur Pedestrian Depan SMP Pangudi Luhur Salatiga

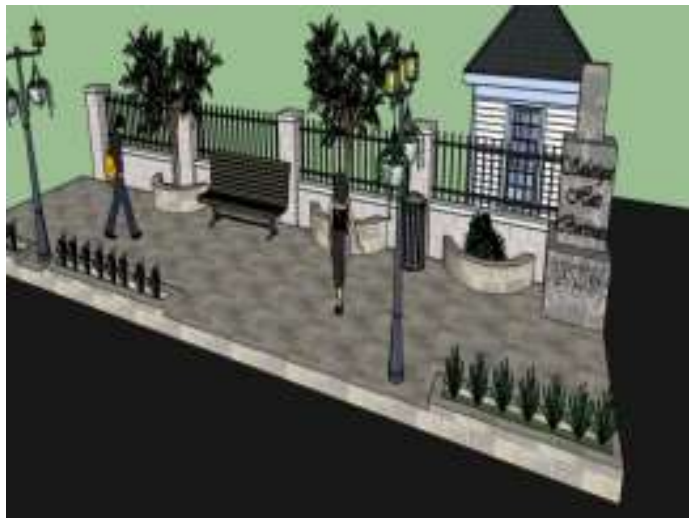

Gambar 3. Desain Ulang Jalur Pedestrian Depan Universitas Kristen Satya Wacana

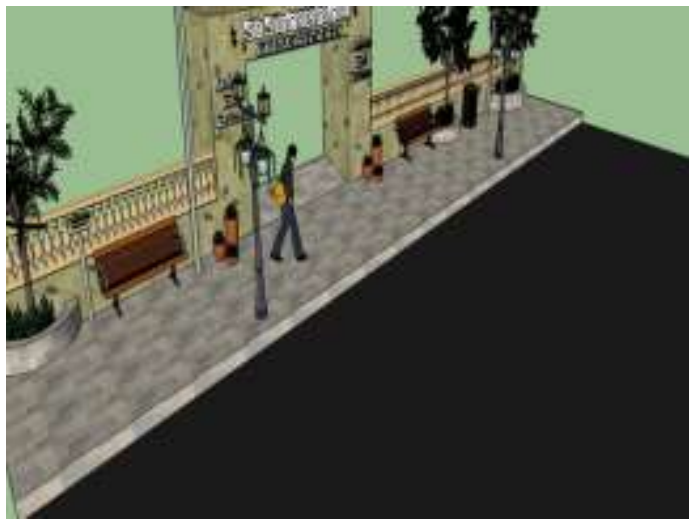

Gambar 5. Desain Ulang Jalur Pedestrian Depan SD Sidorejo Lor I

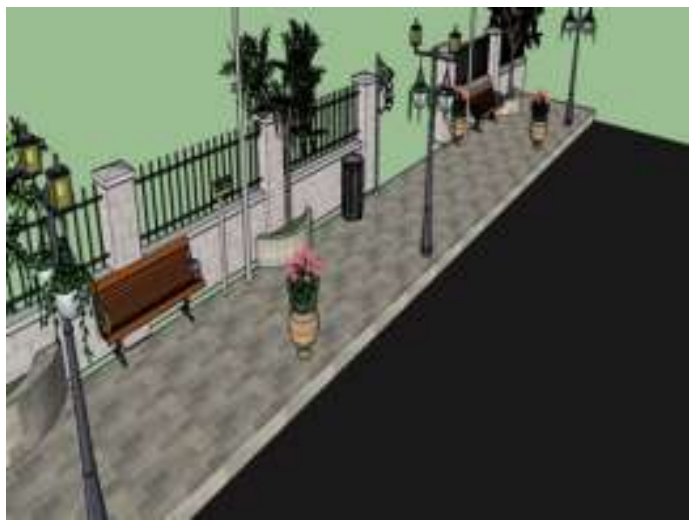

Gambar 6. Desain Ulang Jalur Pedestrian Depan Diponegoro Futsal

c) Prioritas penanganan di jalur pedestrian Jalan Diponegoro Salatiga adalah perawatan vegetasi, fungsi lampu penerangan, kondisi paving dan kebersihan jalur pedestrian.

d) Desain ulang jalur pedestrian di Jalan Diponegoro Salatiga merupakan penataan ulang dengan memprioritaskan aspek fisik yang dianggap pengguna jalur pedestrian masih buruk.

\section{DAFTAR PUSTAKA}

Anas, S. 1996. Pengantar Evaluasi Pendidikan. Raja Grafindo. Jakarta.

Arifin, H.S. 2005. Pemeliharaan Taman. Cetakan VIII Edisi Revisi. Penebar Swadaya, Jakarta. 169 hal.

Direktorat Jenderal Bina Marga. 1990. Petunjuk Tertib Pemanfaatan Jalan. Jakarta. 15 hal.
Direktorat Jendral Bina Marga, Direktorat Pembinaan Jalan Kota. 1990. Petunjuk Perencanaan Trotoar, Direktorat Jendral Bina Marga, Jakarta.

Iswanto, D. 2003. Mengkaji Fungsi Keamanan dan Kenyamanan Bagi Pejalan Kaki di Jalur Pedestrian Jalan Ngesrep Timur V Semarang. Tesis Magister Teknik Arsitektur Universitas Diponegoro Semarang.

Iswanto, D. 2006. Pengaruh Elemen-elemen Pelengkap Jalur Pedestrian Terhadap Kenyamanan Pejalan Kaki. Jurnal Rekayasa Perencanaan. V (1): 21-24

Murtomo, B. 1989. Teori Perancangan Kota. Program Pasca Sarjana ITB. Bandung

Republik Indonesia. 2012. Lampiran Peraturan Menteri Pekerjaan Umum No. 05/PRT/M/2012 tentang 
Pedoman Penanaman Pohon pada Sistem Jaringan Jalan. Menteri Pekerjaan Umum.

Republik Indonesia. 1999. Peraturan Menteri No. 032/T/BM/1999 tentang Pedoman Perencanaan Jalur Pejalan Kaki Pada Jalan Umum. Menteri Pekerjaan Umum

Republik Indonesia. 2014. Peraturan Menteri Pekerjaan Umum No. 03/PRT/M/2014 tentang Pedoman Perencancanaan, Penyediaan, dan Pemanfaatan Prasarana dan Sarana Jaringan Pejalan Kaki di Kawasan Perkotaan. Menteri Pekerjaan Umum.

Republik Indonesia. 2011. Peraturan Daerah Kota Salatiga No 4 Tahun 2011 tentang Rencana Tata Ruang Wilayah Kota Salatiga tahun 2010-2030. Pemerintah Kota Salatiga.

Robbins, S. 2006. Perilaku Organisasi. Edisi kesepuluh. PT.Indeks Kelompok Gramedia. Jakarta

Rubenstein, H. 1992. Pedestrian Malls, streetscapes and urban spaces. John Wiley and Sond. New York

Utomo, N. 2008. Analisa Tingkat Pelayanan Jalur Pejalan Kaki yang Sinergis dengan Fasilitas transportasi public di Kota Surabaya. Jurnal Rekayasa Perencanaan. IV (3): 4

Walgito, B. 2002. Psikologi Sosial. Andi Offset: Yogyakarta 